\title{
Assessing the Presence, Seasonal Dynamicity and Effect of Toxic Plants on Ruminants in Lare and Itang Districts of Gambella Peoples Regional State Southwest Ethiopia
}

\author{
Tsigabu Gebereselassie Gezahegn ", Getahun Asebe Gulich, Wawich Khor \\ College of Agriculture and Natural Resource, Gambella University, Gambella, Ethiopia \\ Email address: \\ fast.golden@gmail.com (T. G. Gezahegn) \\ ${ }^{*}$ Corresponding author \\ To cite this article: \\ Tsigabu Gebereselassie Gezahegn, Getahun Asebe Gulich, Wawich Khor. Assessing the Presence, Seasonal Dynamicity and Effect of Toxic \\ Plants on Ruminants in Lare and Itang Districts of Gambella Peoples Regional State Southwest Ethiopia. Animal and Veterinary Sciences. \\ Vol. 5, No. 5, 2017, pp. 73-83. doi: 10.11648/j.avs.20170505.13
}

Received: January 11, 2017; Accepted: April 7, 2017; Published: October 12, 2017

\begin{abstract}
This study was conducted in "Lare" and "Itang" districts of Gambella People's regional state, South Western Ethiopia and assessed the presence, seasonal dynamicity and effect of toxic plants on large and small domestic ruminants. A cross sectional type of research was used to survey potential toxic plants for domestic animals from January 2016 to August 2016 with the help of a structured questionnaire format and plant sampling. A total of 255 individuals were interviewed (151 from "Lare" and 104 from "Itang"), of which $80.4 \%$ are males. Both infectious and non-infectious types of diseases challenge the livestock production system in the area (with $65.0 \%, 30.8 \%$, combination of infectious and non-infectious and infectious diseases alone respectively), despite more than $60.4 \%$ said disease is the main livestock rearing obstacle in the areas. About $88.4 \%$ said cases of toxic plants mostly occur once per year while, very few of the participants said toxic plants as the problem, that occurs most often and often (8.2\%, and 3.4\% respectively). Shrubs are main source of plant toxicosis (97.3\%). Of the total (146) participants, about $63.0 \%$ of them said, they attempt to treat locally/traditionally, while only $32.2 \%$ visits modern veterinary service. Among the top mentioned pre-disposing factors that expose animals for plant toxicosis in the study area were, food shortage (43.2\%), accidental ingestion with feed (40.4\%), nutritional deficiency (6.8\%), and excess consumption (4.8\%). The most common likely period of the year that plant toxicosis occur in general; beginning of wet season (48.6\%), end of rainy season $(32.9 \%)$, end of the dry season $(12.3 \%)$ and peak of dry season $(2.7 \%)$. Cattle, sheep and goats are among the susceptible and can cause various illness and also cause sudden death to them. Among the non-infectious diseases, plant poisonings are one of the non-infectious livestock health problems in the study areas, that resulting huge loss when animals graze in poisonous plant. Some of the identified toxic plants in the area includes Ngiar, Wath (Sorghum arundinaceum), Diir, Magak (Lactuca inermis Forssk), Nyuath and Zom (Ipomoea acquatica Forssk). Other toxic plants identified were Dep gany (Cissus quadrangularis L.), Tach Yaaz (Ipomoae acuatica Forssk) and Hygrophilla schulli (hamilt.) MR. \& S. M Almeida species. Proper attention and further toxic plants epidemiological investigations should be conducted for minimizing the direct and indirect loss to the livestock sector in the region.
\end{abstract}

Keywords: Toxic Plant, Season, Risk Factors, Non-infectious, Shrubs

\section{Introduction}

\subsection{Background}

Many studies showed that toxic plants affecting both large and small animals are a major concern for the practicing veterinarian and livestock producer in every country of the world. In countries with higher plant biodiversity, the number of problematic toxic plants may be greater (Diaz, 2011), despite there are plants that played a central part in combating many aliments in human and livestock in many indigenous communities, in the world including Africa 


\section{(Bussmann et al., 2011)}

Plants have played a central part in combating many ailments in human and livestock in many indigenous communities, including Africa. Ethiopia, which is located in the Horn of Africa between 3 to $15^{\circ} \mathrm{N}$ and 33 to $48^{\circ} \mathrm{E}$ longitude is a country with varied climatic conditions. The temperature varies from $10^{\circ} \mathrm{C}$ to $45^{\circ} \mathrm{C}$ (Tamire, 1997). This varied climatic condition enables the country to have diverse flora and fauna that are unique of which $12 \%$ are endemic. Despite the fact the forest is declining in size and quantity, the contributions to the national and local economy from forest resources are of immense value (WBISP, 2004).

Though plants do have advantages for human and animals as a food, medicinal values, some of the floras have also toxic effects in animals and humans (Clarke and Clarke, 1977).

Plants take the third largest category of poisons known around the world. The effect of this toxic plants on animals amplified as they form a major part of livestock feed, thus toxicosis in animals consuming these plants can be expected (Clarke and Clarke, 1977). Forage crops may sometimes contain compounds that may inadvertently affect animals. Several factors contribute to an animal being poisoned by plants. Fundamentally, there is the requirement that a sensitive species of animal ingest, or otherwise be exposed to, a toxic plant at an appropriate time. There are many examples of species differences with regard to sensitivity to the toxic effects of plants. In addition, it is possible for animal species to adapt to a potentially toxic plant if exposure is allowed to occur over a period of time. Disease problems are most commonly caused by forage contaminated with poisonous weeds.

Even though animals are selective about what they eat, there are instances (for example, herbicide applications) that may change palatability or increase toxicity of some plants. If weeds are embedded in hay cubes, animals may not be able to avoid ingestion of the weeds. Major economic constituted due to losses through the poisonous plants in economic loss in the livestock industry since the days of early settlement (Clarke and Clarke, 1977).

The loss may be in the form of, mortalities, production, veterinary service fees or a combination of two or more of these losses (Oguwag, 1977). The symptoms and lesions differ observed on the affected animals depending on the amount of theplant consumed, age, and species of the animals. Despite the variation in their effect the common clinical signs and symptoms, however include death, chronic illness and debilitation, decreased weight gain, abortion, abdominal discomfort, salivation, congenital defects, photosensitization (Clarke and Clarke, 1977). These symptoms have been attributed to the toxic principle in such plants, which range from nitrates, oxalate, fluroacetate, selenium etc. Both large and small animals are frequently affected by toxic plants and they are a major concern for the practicing veterinarian and livestock producer in every country. In countries with higher plant biodiversity, the number of problematic toxic plants may be greater. In a study conducted near Central Ethiopia by Abera et al. (2014) indicated that $68.8 \%$ of the respondents showed as the toxic plants are major livestock problems in the area.

The major challenging issue in case of plant toxicosis is the type of farming system farmers or livestock owners practicing. In countries like Ethiopia in general and Gambella Regional State in particular where livestock owners practicing extensive farming system present the chance of animals intoxicated with toxic plants high. All of the livestock in this region is kept under extensive system, making them susceptible for poisoning by toxic plants. With the current increasing human activities such as construction, farming, deforestation and other forms of environmental degradation, which affects the fauna and the flora, it becomes very important to assess common poisonous plants found in the region.

\subsection{Statement of the Problem}

In most parts of the world, in particular in Eastern Africa like the Ethiopia variety of poisonous plants have caused extensive losses to the livestock industry since early settlement times. These toxic plants are still results significant impact in many areas. These poisonous plants produce their toxic effects after being ingested and/or absorbed by animals (Radeleff, 1964) which include physical upset, loss of productivity and death. Having the fact that plants have vital nutritious and providing the normal atmospheric oxygen, it will cause also life threatening if it is toxic and poisonous (Bah, 2013).

The major problem of plant poisoning is due to the animals either accidental ingest of material eaten along with grass or willful consumption of poisonous plants when pasture is dry as most poisonous plants remain green all the year round while edible once dry away. Specially areas where diverse vegetation and animals graze beyond the close supervision of the attendants, feed shortage seasons, when animal's moves from one part of the country to another during feed shortage and trade (Mugera, 1987). Factors that expose animals for plant toxicosis are feed shortage which can force animals to browse perennial shrubs and bushes while most of these perennial plants have been known to contain toxic secondary metabolites (Seifert, 1969).

Various studies in different parts of the world showed as toxic plants do have various impacts on the animal health. Some of the impacts of the toxic plants includes, irritation and disorders of oral cavity and digestive system, causing haemolytic anemia, Methemoglobinemia(normal ferrous moiety $\left(\mathrm{Fe}^{2+}\right)$ oxidized to the abnormal ferric form $\left(\mathrm{Fe}^{3+}\right)$ ), causing coagulation of blood, cardio toxicity, hepatotoxicity, necrosis of the hepatic cells, causing Intrahepatic Cholestasis, affecting the urinary system, causing disorder in the nervous system (Block the Neuromuscular Junction, Affect the Central Nervous System (CNS), Cause Neurological Signs, Inducing Thiamine Deficiency), affecting the Musculoskeletal System and Connective Tissue, affecting the Skin, affect Reproduction, Containing Systemic Poisons, etc (Diaz, 2011). Areas like Gambella where there is diverse 
plant species available, the risk of small and large animals being intoxicated will be high, where the result will contribute in reducing the problems of losing after toxic plants.

\subsection{Research Questions}

This research is expected to answer the following main questions:

a) Are there toxic plants in the study areas?

b) Which species of animals are affected severely by the toxic plants?

c) In which seasons of the year the toxic plants produce high impact?

d) What are the major impacts of toxic plants in the area?

e) Which botanic groups of plants dominantly found in the area?

f) Do the animal owners do have the awareness of toxic plants in the area?

g) What kinds of problem tackling are animal owners are practicing in the area?

\subsection{Research Objective}

This study was conducted with the following general and specific objectives.

General Objective

The general objective this study was

To assess the presence, seasonal dynamicity and effect of toxic plants on large and small domestic ruminants in Lare and Itang Districts of Gambella Regional State Southwest Ethiopia.

\section{Materials and Methods}

\subsection{Research Location and Description of the Study Area}

This study was conducted in two districts of the Gambella peoples' Regional States called Lare Woredas of Nuer Zone and Itange Special Woreda.

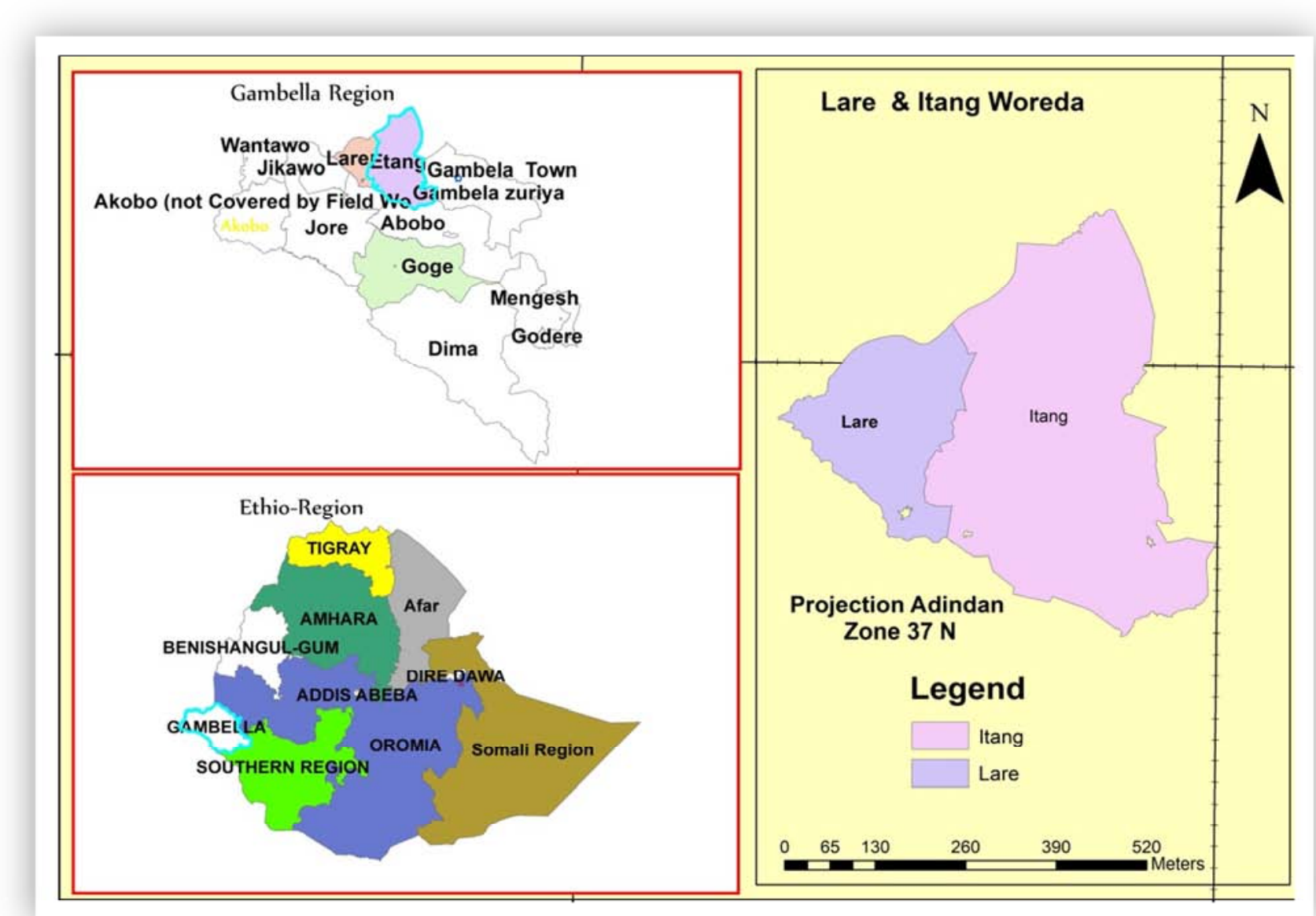

Figure 1. Maps of the study areas.

The region is located in the southwest part of Ethiopia, situated in the lowlands of the Baro-Akobo River Basin between latitudes $6^{0} 22^{\prime}$ and $8^{0} 30^{\prime} \mathrm{N}$, and longitudes $33^{\circ} 10^{\prime}$ and $35^{\circ} 50^{\prime} \mathrm{E}$, and covers a total area of about 34,063 square kilometers (GRS, 2003). The regional state is characterized as mild, lowland and semi-desert agroecological zones.

The annual rainfall and mean annual temperature in the 
Regional State are $1,247 \mathrm{~mm}$ and $34.37^{\circ} \mathrm{C}$, respectively (IAR, 1990). The rainfall regime is unimodal, referred to as the "Sudan Type", occurs in the lowlands along the border with Sudan (Coppock, 1994). Poorly drained vertisol is the characteristic soil type of the grassland (GRS, 2003). The highest livestock population in Tropical Livestock Unit (TLU) is found in

Jikawo district 156,168.5 (53\%), followed by Akobo, $114,390.8(39.3 \%)$. The lowest TLU in Gog, which is, $1,341.6(0.5 \%)$ (PADS, 2004). The major breed is the Nuer (zebu) which is a very good performer in dairying and beef production provided proper management levels (GRS, 2003) and considered to have a high tolerance to tsetse challenges (Alemayehu, 2004).

Lare Woreda is also located in Nuer zone of the Gambella region, Lare is one of the woreda as in the Gambella Region of Ethiopia. Part of the Nuer Zone, Lare is bordered on the south and east by the Anuak Zone, on the west by the Baro River which separates it from Jikawo, and on the north by the Jikawo River which separates it from South Sudan. Towns in Lare include Kowerneng (GBOA, 2007).

The small and large domestic ruminants population size of the region based on the CSA (2012) report the cattle population of the Gambella Region as 251,367, out of this about 183,363 of them is found in Nuer zone whereby this research was conducted and 33,582 cattle in Itang special woreda. While the small ruminant populations were also found in these study sites. From the total small ruminants 130,225 sheep and goats 96,717 are found in Nuer zone, and 17, 093 in Itang special Woreda, while the rest large and small ruminants located in Mezenge and Agnuwa zones.

Livestock Production System of the Area

The production system of the region is mainly livestock rearing and seldom crop production. Almost all the animals reared by smallholder farmers in extensive system. The livestock populations owned by the farmers are large in number.

\subsection{Research Type}

Cross sectional type of research was used to survey potential toxic plans for domestic farm animals from January 2016 to August 2016 in the selected districts of Gambella Regional State.

\subsection{Study Design}

A structured questionnaire was prepared to survey the potential toxic plants in the two districts Lare and Itang special woreda for the animal owners. Besides the samples of toxic plants were collected and taken to Addis Ababa University, faculty of science for botanical grouping.

\subsection{Data Sources}

This research generated primary data from farmers, animal health practitioners, key respondents and plant samples in the field.

\subsection{Data Collection Instruments}

The data collection methods were structured questionnaire, prepared checklists, pencils \&pens, papers, digital camera, $\mathrm{CD} /$ Flash, bags, markers, etc.

\subsection{Sampling Frame/Population}

The target study populations were voluntary animal owners.

\subsection{Sampling Technique}

Purposefully we selected three kebeles from each woreda/district based on the livestock rearing practice. From each kebele we took, voluntary respondents both from the animal owners and from animal health practitioners.

\subsection{Sample Size}

Based on the Abera et al. (2014) in a study conducted in the East Showa Adama area, Ethiopia, the current sample was 255 voluntary animal owners employed.

The sample size estimated to be 255 using the following formula (Thrustfield, 2007),

$$
\mathrm{N}=\frac{\mathrm{Z}^{2} \frac{\alpha}{2} \mathrm{P}(1-\mathrm{P})}{\mathrm{d}^{2}}=\frac{1.96^{2} * 0.8(1-0.8)}{0.05^{2}}=255
$$

Where $\mathrm{N}=$ number of respondents of the animal owners

$\mathrm{P}=$ Proportion of people who were respond to the household questionnaire about the toxic plants for small and large ruminants in the two study districts.

$\mathrm{Z}=1.96$ at $95 \%$ confidence interval

$\mathrm{d}=$ expected margin of errors, i.e. 0.05

$\mathrm{N}=$ required sample size

The total sample size is 255 .

\subsection{Methods of Data Analysis}

The information that was gathered through questionnaire survey of suspected toxic plants entered into the Microsoft Excel program. To identify the scientific names of the complainants poisonous plants the National Herbarium of Biology, Department of Science Faculty, Addis Ababa University was consulted. The data was analyzed by descriptive statistics using SPSS version 16.0.

Data Quality Control

During data collection in the field and at the end of each day, the questionnaires reviewed and checked for completeness, accuracy and consistency by the investigators and corrective measures were taken.

Plant samples information for identification of their botanical group were taken curiously, such as ecological preferences, local names, village, kebele...etc.

\subsection{Working Permission}

Working permission was obtained from the respective woreda administration office by holding a letter of support from the Gambella University Research and Community service Directorate office. 


\subsection{Descriptive Variables}

Table 1. List of Descriptive Variables.

\begin{tabular}{ll}
\hline Dependentvariable & Independentvariables \\
\hline Toxicplant'spresence & Speciesoftheanimal \\
Riskfactor & Age \\
Knowledge, Attitude of the & Sex \\
practices of the society & Season \\
Impactofthetoxicplants & Partsoftheplant (leaf, root, fruit.) \\
Parts of the plant & Educationallevel \\
Habitat of the plant & Experience \\
& Dosage \\
& Speciesoftheanimal \\
& Seasonoftheyear \\
& Location \\
\hline
\end{tabular}

The independent variables of this study were the socioeconomic characteristics of the population, species of the animal, season of the year, location etc while the types of toxic plant, dependent variables, parts, knowledge and attitude practice of the society etc.

\section{Results}

\subsection{Socio-demographic Characteristics of the Study Participants}

A total of 255 individuals were interviewed (151 from Lare, and 104 from Itang), of which $80.4 \%$ are males. (Figure 1).

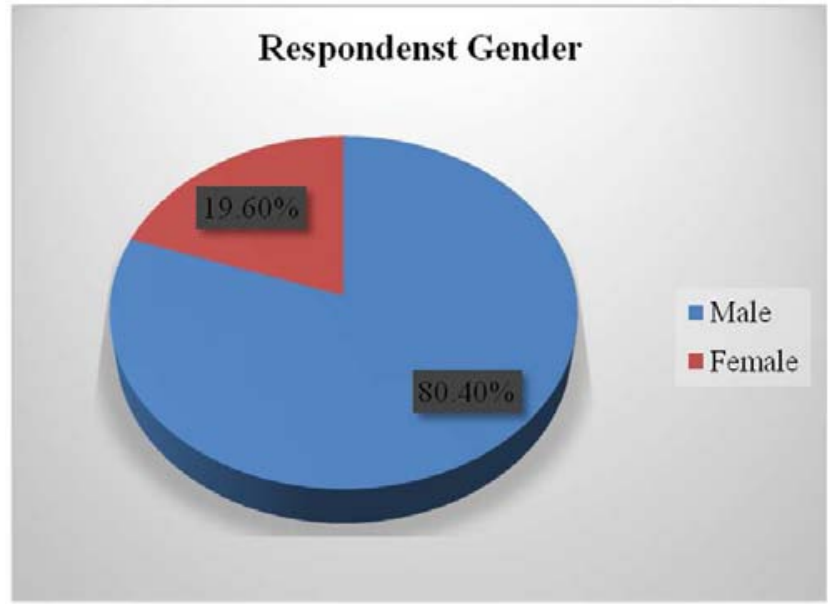

Figure 1. Respondents Gender in the two districts of Lare and Itang Special Woreda.

Almost 94.5\% (241) are married with low percentages of unmarried and divorced, $1.2 \%$, and $2.4 \%$ respectively, using structured questionnaires. The proportions of respondents were 3 kebeles from each woreda. About $88.8 \%$ of the respondents' are engaged farming activity while only $6.3 \%$ are civil servants in the woredas among the study participants (Table 1).

Table 2. Socio demographic characteristics of the respondents.

\begin{tabular}{|c|c|c|c|c|c|}
\hline Characteristics & Frequency (N) & Percent (\%) & Characteristics & Frequency $(\mathbf{N})$ & Percent (\%) \\
\hline \multicolumn{3}{|l|}{ Sex of the respondents } & \multicolumn{3}{|l|}{ Educational Status } \\
\hline Male & 205 & 80.4 & Not writing and reading & 151 & 59.2 \\
\hline Female & 50 & 19.6 & Writing \& reading (informal) & 16 & 6.3 \\
\hline \multicolumn{3}{|l|}{ Marital status } & $1-4$ grade & 23 & 9.0 \\
\hline Married & 241 & 94.5 & 5-7 grade & 24 & 9.4 \\
\hline Unmarried(never) & 3 & 1.2 & $8-12$ grade & 29 & 11.4 \\
\hline Divorced & 6 & 2.4 & certificate and above & 12 & 4.7 \\
\hline Other & 5 & 2.0 & & & \\
\hline \multicolumn{3}{|c|}{ Occupation status of the respondents' } & \multicolumn{3}{|l|}{ Kebele of the respondents } \\
\hline Farmer & 226 & 88.6 & Kutogni (lare) & 50 & 19.6 \\
\hline Civil servant & 16 & 6.3 & Bilimkun (lare) & 50 & 19.6 \\
\hline Merchant & 10 & 3.9 & Reak (lare) & 51 & 20.0 \\
\hline \multirow[t]{3}{*}{ Other } & 3 & 1.2 & Pilual (itang) & 34 & 13.3 \\
\hline & & & Pulkot (Itang) & 37 & 14.5 \\
\hline & & & Itangkir (Itang) & 33 & 12.9 \\
\hline \multicolumn{6}{|c|}{ How many years you lived in the area } \\
\hline Less than 5 years & 51 & 20.0 & & & \\
\hline More than five years & 204 & 80.0 & & & \\
\hline
\end{tabular}

\subsection{Farming Activity in the Area}

Study participants mainly engaged in both livestock and crop production mainly compared to livestock farming, $24.7 \%$ and $75.3 \%$ respectively in the study areas. Almost many of the study participants own cattle in the livestock structure and very few only have sheep and goats alone. The main feed source of livestock in the study areas are shrubs types of plants compared to the tree sources $(84.7 \%)$ as shown in Table 2. 
Table 3. Farming activities, Livestock owned, and type of feed animals consume.

\begin{tabular}{lll}
\hline Variable & Frequency (N) & Percent (\%) \\
\hline what is your current farming activity & & \\
Livestock only & 63 & 24.7 \\
Both livestock \& crop & 192 & 75.3 \\
Which species of domestic animals & & \\
do you own? & & \\
Cattle & 64 & 25.1 \\
Sheep & 4 & 1.6 \\
Goats & 7 & 2.7 \\
cattle, sheep, goats, poultry & 63 & 24.7 \\
cattle \& sheep & 10 & 3.9 \\
cattle, goats & 30 & 11.8 \\
cattle, sheep, goats & 23 & 9.0 \\
Cattle, goats \& poultry & 33 & 12.9 \\
Cattle\& poultry & 9 & 3.5 \\
Sheep \& poultry & 1 & .4 \\
Goats \& poultry & 1 & .4 \\
Cattle, Sheep 7 poultry & 10 & 3.9 \\
where your livestock most of the & & 84.7 \\
time grazes in the area & & .8 \\
Shrubs & 216 & 14.5 \\
Tree & 2 & \\
Shrubs and Tree & 37 & \\
\hline
\end{tabular}

\subsection{Livestock Rearing Constraints}

Table 3 below illustrates the major livestock rearing problems. About $60.4 \%$ of the participants indicated presence of diseases is the primary challenging followed by absence of animal feed $(5.9 \%)$. The remaining challenges are the combinations of different factors. Both infectious and noninfectious types of disease challenges the livestock production system in the area (with 65.0\%, 30.8\%, combination of infectious and non-infectious, infectious diseases alone respectively) (Table 3).

Table 4. Major livestock rearing constraints in the study areas.

\begin{tabular}{lll}
\hline Variable & Frequency (N) & Percent (\%) \\
\hline $\begin{array}{l}\text { what are the major ruminants rearing } \\
\text { problems in the area(N=255) }\end{array}$ & 154 & 60.4 \\
$\begin{array}{l}\text { Presence of diseases } \\
\text { Absence of animal feed }\end{array}$ & 15 & 5.9 \\
Disease and animal feed & 18 & 7.1 \\
$\begin{array}{l}\text { Disease and water } \\
\text { Disease, water, and animal feed }\end{array}$ & 99 & 3.5 \\
$\begin{array}{l}\text { if your response is presence of diseases } \\
\text { for question number what kind of } \\
\text { diseases (N=240) }\end{array}$ & 23.1 \\
$\begin{array}{l}\text { Infectious types of diseases } \\
\text { Non-infectious types of diseases }\end{array}$ & 74 & \\
Infectious and non-infectious & 10 & 30.8 \\
\hline
\end{tabular}

\subsection{Toxic Plants in the Study Areas}

About $13.9 \%$ of the participants mentioned toxic plants are among the non-infectious diseases, while others mentioned toxic plants as combination of toxic plants and other factors. Nutritional disorders $(6.0 \%)$ and congenital problems $(3.0 \%)$ are among the other non-infectious diseases mentioned by the participants. Among the 146, who mentioned toxic plants as a livestock health problem alone or in combinations with other factors, most of (88.9\%) said the problem occurs once in a year. Very few of the participants said toxic plants as the problem, that occurs most often and often $(8.2 \%$, and $3.4 \%$ respectively). Shrubs are main source of plant toxicosis (97.3\%) (Table 4).

Table 5. The contribution, seasonal frequency, common plant groups in the study area.

\begin{tabular}{lll}
\hline If non-infectious (N=166) & Frequency (N) & Percentages (\%) \\
\hline Nutritional disorder & 10 & 6.0 \\
Congenital problems & 5 & 3.0 \\
Toxic plants & 23 & 13.9 \\
Nutrition \& congenital problems & 5 & 3.0 \\
Nutritional and toxic plant & 34 & 20.5 \\
Non-genital and toxic & 28 & 16.9 \\
All the three & 61 & 36.7 \\
Frequency of toxic plant & & \\
occurrences (N=146) & & \\
Three time per year(most often) & 12 & 8.2 \\
Two times per year(Often) & 5 & 3.4 \\
One time per year (Seldom) & 129 & 88.4 \\
Common plant groups sources of & & \\
toxicosis for livestock (N=146) & & \\
Shrubs & 142 & 97.3 \\
Trees & 1 & 0.6 \\
Both shrubs and trees & 3 & 2.1 \\
\hline
\end{tabular}

\subsection{Common Remedial Measures Taken by the Participants in the Area}

Of the total (146) participants, about $63.0 \%$ of them said, they attempt to treat locally/traditionally, while only $32.2 \%$ visits modern veterinary service (Table 5).

Table 6. Common remedial measures for plant toxicosis and other diseases in the study area.

\begin{tabular}{lll}
\hline $\begin{array}{l}\text { Measures after animals get plant } \\
\text { toxicosis (N=146) }\end{array}$ & Frequency (n) & Percentage(\%) \\
\hline Treat by local/traditional medicines & 92 & 63.0 \\
Visit animal health professionals & 47 & 32.2 \\
Leave to cure by itself & 5 & 3.4 \\
$\begin{array}{l}\text { Both traditional and veterinary } \\
\text { clinics }\end{array}$ & 2 & 1.4 \\
\hline
\end{tabular}

Equally with the toxic plants, participants try to tackle other infectious and non-infectious diseases locally/traditionally $(63.9 \%)$ and through modern veterinary treatment $(32.2 \%)$ (Figure 2). 


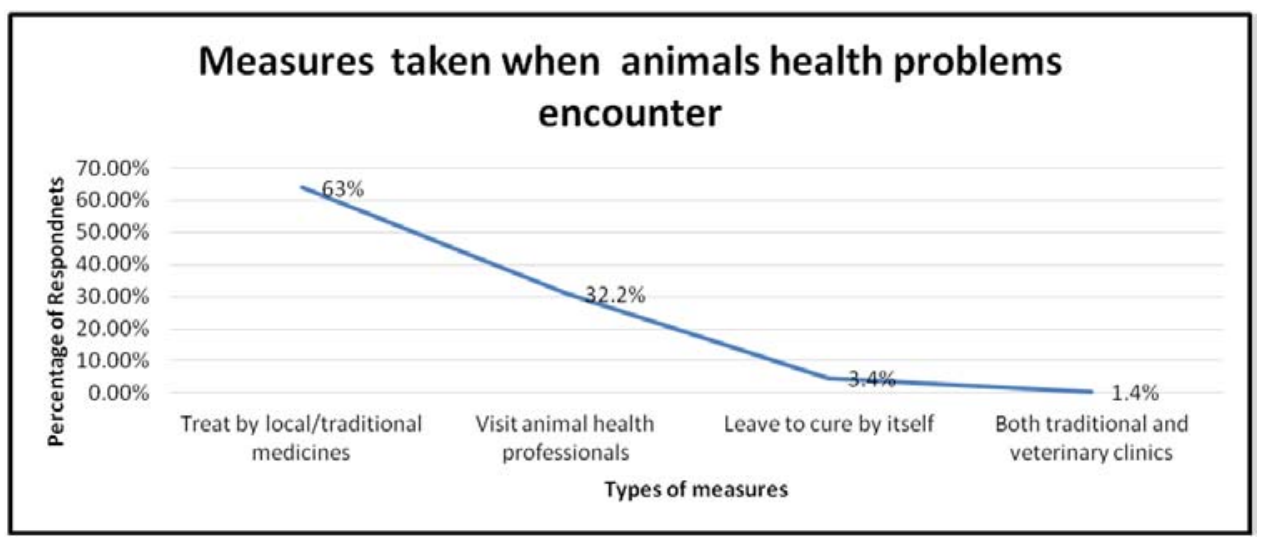

Figure 2. Measures taken by respondents when other than toxic plants health problems encounter.

\subsection{Risk Factors, Occurrence Season, for Plant Toxicosis in the Area}

Among the top mentioned pre-disposing factors that expose animals for plant toxicosis in the study area were, food shortage (43.2\%), accidental ingestion with feed (40.4\%), nutritional deficiency $(6.8 \%)$, and excess consumption $(4.8 \%)$. The most common likely period of the year that plant toxicosis occur in general; beginning of wet season $(48.6 \%)$, end of rainy season $(32.9 \%)$, end of the dry season $(12.3 \%)$ and peak of dry season $(2.7 \%)$. Regarding the high availability of toxic plant; participants mentioned wet season $(97.3 \%)$ is highly preferred for the occurrence of toxic plants (Table 6).

Table 7. Pre-disposing factors, seasonal preferences and occurrence of toxic plants in the study areas.

\begin{tabular}{|c|c|c|}
\hline Variable & Frequency $(\mathbf{N})$ & Percent (\%) \\
\hline \multicolumn{3}{|c|}{$\begin{array}{l}\text { The pre-disposing factors for the exposure } \\
\text { of animals for plant toxicosis }(\mathrm{N}=146)\end{array}$} \\
\hline Food shortage & 63 & 43.2 \\
\hline Nutritional deficiency & 10 & 6.8 \\
\hline Excess consumption & 7 & 4.8 \\
\hline Accidental ingestion with feed & 59 & 40.4 \\
\hline Unknown reason & 1 & 0.7 \\
\hline $\begin{array}{l}\text { Food shortage \& Accidental ingestion } \\
\text { with feed }\end{array}$ & 1 & 0.7 \\
\hline $\begin{array}{l}\text { Nutritional \& accidental ingestion with } \\
\text { feed }\end{array}$ & 1 & .7 \\
\hline \multicolumn{3}{|l|}{$\begin{array}{l}\text { Common period of the year plant } \\
\text { toxicosis most likely occur in general } \\
(\mathrm{N}=146)\end{array}$} \\
\hline Beginning of wet season & 71 & 48.6 \\
\hline End of rainy season & 48 & 32.9 \\
\hline Peak of the wet season & 1 & .6 \\
\hline Beginning of dry season & 2 & 1.4 \\
\hline End of the dry season & 18 & 12.3 \\
\hline Peak of dry season & 4 & 2.7 \\
\hline $\begin{array}{l}\text { Beginning of wet season, end of rainy } \\
\text { season }\end{array}$ & 2 & 1.4 \\
\hline \multicolumn{3}{|l|}{$\begin{array}{l}\text { Availability season of the toxic plant } \\
(\mathrm{N}=146)\end{array}$} \\
\hline wet season & 142 & 97.3 \\
\hline dry season & 3 & 2.1 \\
\hline all year round & 1 & .6 \\
\hline
\end{tabular}

\subsection{Species Affected and Common Areas Where Toxic Plants Located}

Livestock species affected due to toxic plants according to the participants include cattle $(28.1 \%)$, goats $(1.4 \%)$, sheep $(0.7 \%)$, and combination of cattle, sheep \& goats. Toxic plants are located in the riverbank (watering point) $(43.8 \%)$, rangeland $(23.3 \%)$, backyard $(15.8 \%)$, and farmland $(14.4 \%)$ (Table 7).

Table 8. Frequently affected domestic animals and common locations of the toxic plants in the study area.

\begin{tabular}{lll}
\hline Species Affected $(\mathbf{N}=146)$ & Frequency & Percentage \\
\hline Cattle & 41 & 28.1 \\
Goats & 2 & 1.4 \\
Sheep & 1 & .6 \\
cattle, sheep, goat & 75 & 51.4 \\
cattle \& goats & 13 & 8.9 \\
goats and sheep & 14 & 9.6 \\
common location of the toxic plant $(\mathrm{N}=146)$ & & \\
Range land & 34 & 23.3 \\
Farm land & 21 & 14.4 \\
River bank/water point & 64 & 43.8 \\
Back yard & 23 & 15.8 \\
Farm land \& river bank/water point & 4 & 2.7 \\
\hline
\end{tabular}

\subsection{Toxic Body Part, Exposures, and Impacts of Toxic Plants for Animals}

The toxic body parts of plants in this study based on the participants' response include from top to low proportions; leaves $(50.7 \%)$, whole plant $(31.5 \%)$, leaves and stem $(16.4 \%)$ and juice (1.4\%) (Figure 3). A single exposure to toxic plant can affect the animal according to $68.5 \%$ participants' response, while $31.5 \%$ said there should be a repeated exposure for abnormal changes on the animals (Figure 4).

The impact of toxic plants extends from simple signs $(30.1 \%)$, organ impairment $(24.7 \%)$, production decrement (24.7\%) and death (20.5\%) (Figure 5). 


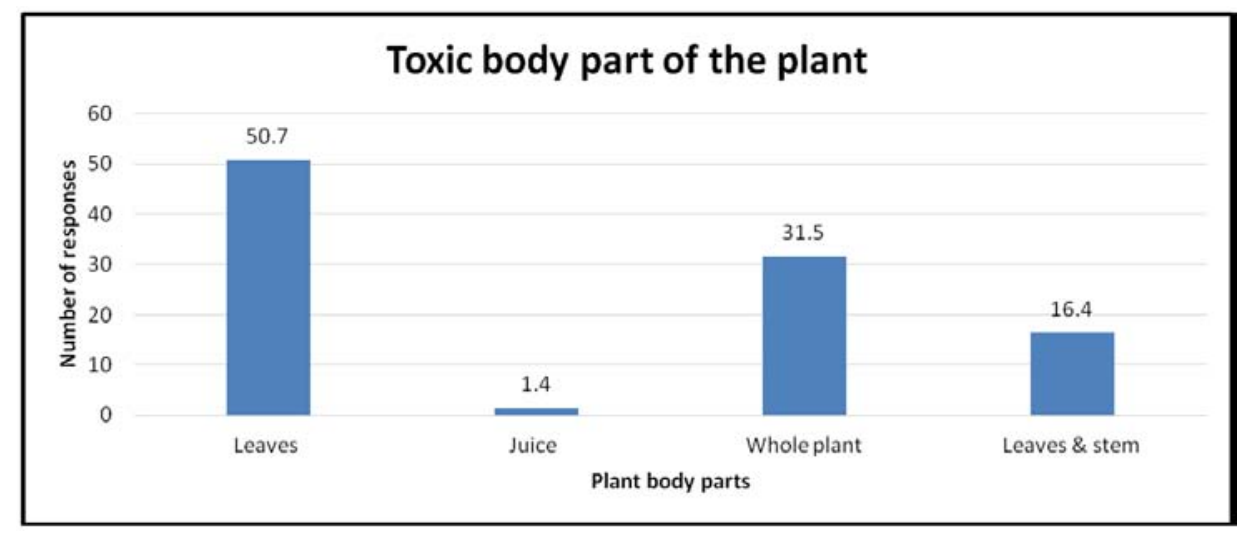

Figure 3. Toxic plant body parts according to the response of study participants in Lare and Itang.

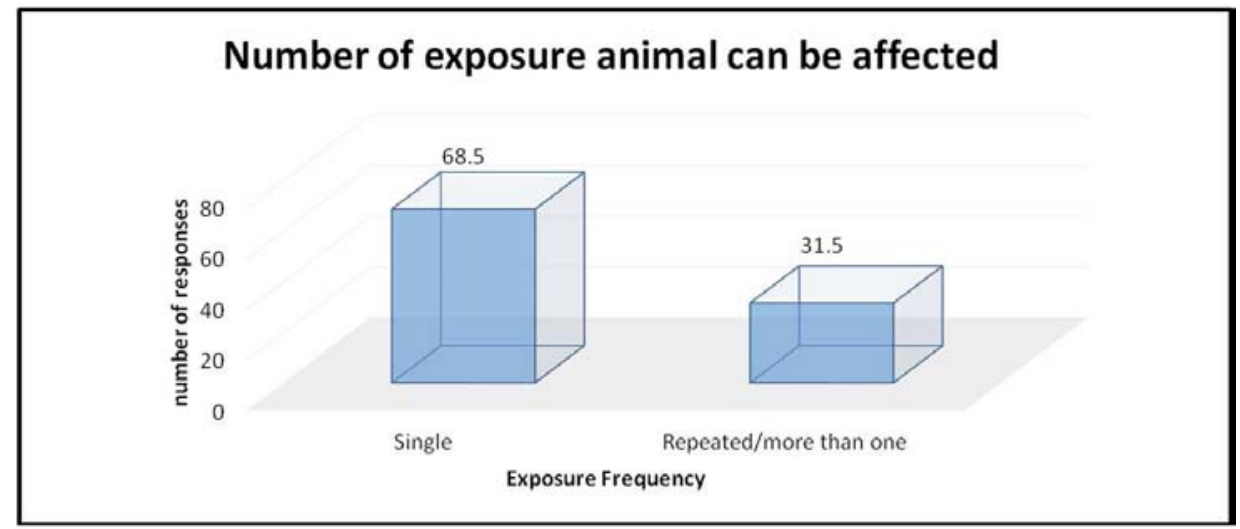

Figure 4. Number of exposures that can affect an animal according to the response of study participants.

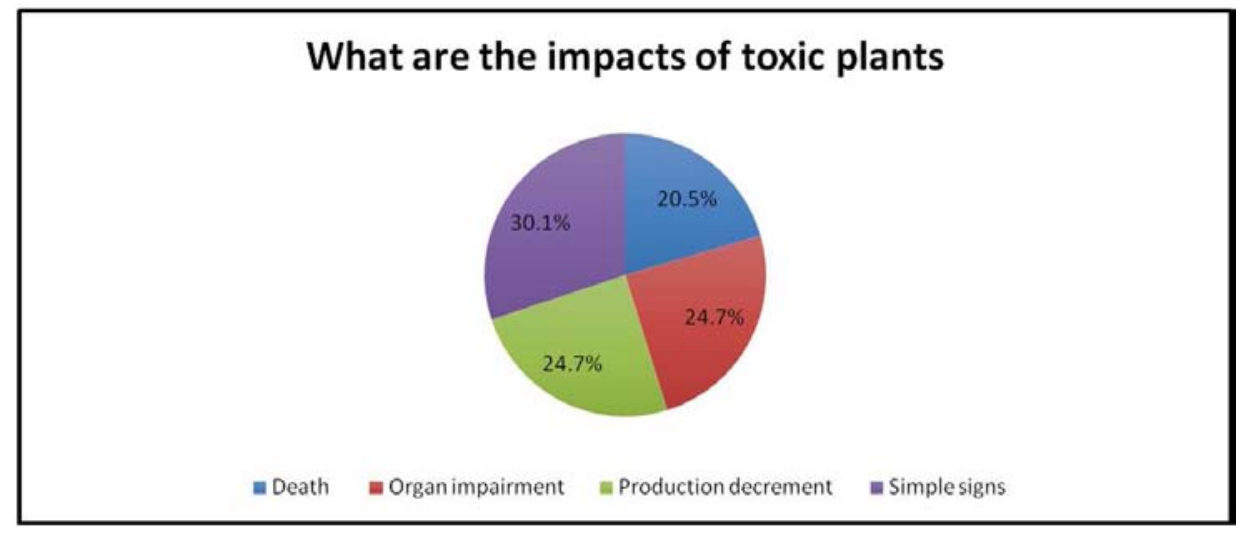

Figure 5. Impacts of toxic plants on the animal according to the response of study participants.

\subsection{Qualitative Approach of Experts Opinion About Plant Toxicosis}

There were two experts at animal health assistant level, one for each district who were active at the job and responded for this study. Qualitatively explaining, the experts mentioned the presence of toxic plants in the area. This toxic plants available both during dry and wet season. The livestock species commonly affected by these plants based on the experts opinion includes cattle, sheep and goats, with the age groups ranging from one two three years, despite the impact extends from young to adults. Animals affected with the toxic plants showed sudden death, various sickness and production impairments despite the fact the sudden death is most frequent occurrence. Cases of toxic plants are more frequently occur at the beginning and end of dry season, peak of dry season in the study areas based on the experts' opinion. The common sources of plant toxicosis according to the responses of experts were both wild and domestic plants despite the wild contributes the vast majority of the proportions. Among the plant groups, the shrubs are among the top mentioned that become sources of plant toxicosis. The pre-disposing factors in the study areas based on the experts' opinion for plant toxicosis were accidental ingestion 
with feed, animal feed shortages and excess consumptions.

\section{Discussion}

The farming activity in the current study areas was dominated by mixed farming system of both livestock and crop production $(75.3 \%)$ of the participants agreed. Among the livestock farming system, cattle rearing are widely practiced, despite goats, sheep and poultry also reared in the area. Animals graze more in shrub $(84.7 \%)$ than plants tree species.

Among the major problems in these study areas were animal health challenges including diseases (60.4\%), scarcity of animal feed $(5.9 \%)$ and water shortage. Besides these independent problems, in vast majority of the study participants, combinations of different constraints such as diseases (infectious and non-infectious), scarcity of animal feed $(5.9 \%)$ and water shortage $(60.4 \%)$ is playing a great impact on the animals production and productivity in the areas. The problems of both infectious and non-infectious diseases on livestock in the study areas are high according to the study participants $(65.0 \%)$ response.

This research result showed as non-infectious problems such as toxic plants among the toxicosis of livestock. In this study, non-infectious diseases caused by toxic plants are the health challenges of livestock mentioned by $13.9 \%$ of the participants alone. Toxic plants in combination with other factors such as congenital and nutritional deficiency took $74.1 \%$ of the problem share. Independently looking, nutritional disorders $(6.0 \%)$ and congenital problems $(3.0 \%)$ are among the other non-infectious diseases mentioned by the participants (Abera et al., 2015; Abera et al., 2014; Kebede et al. (2015). The result was also similar with other studies conducted outside from Ethiopia, (Adediwura and Kola, 2012) in Nigeria; (Torres et al., 2012) in Colombia; (Durairaj, 2012) in Tiruchrapalli districts of Tamil Nadu, South India. The current study indicated the impacts of toxic plants with other non-infectious and infectious diseases in the South West Ethiopia. Similar findings were also seen in various locations of Ethiopia and other parts of the world. Some of the studies with similar findings in Ethiopia.

The most common likely period of the year plant toxicosis occur in general in this study were: beginning of wet season $(48.6 \%)$, end of rainy season $(32.9 \%)$, end of the dry season(12.3\%) and peak of dry season(2.7\%). Based on the present study result, which is similar with Abera et al. (2015) in the seasonal occurrence of toxic plants, most of them occur during the end of rainy season. Regarding the availability of toxic plant, $97.3 \%$ of the participants mentioned wet season is highly preferred for the occurrence of toxic plants. Other study showed animals usually poisoned at the start and end of rainy season and during the dry season (Abera et al., 2015). This may be due to the area is known to have long rainy season, most of the plant species grow within this period of time and the chance that animals to pick this plant species with other regular feed might be high. Towards the frequency of toxic plants occurrences, $88.4 \%$ said they once per year, which is seldom in availability, even though, there are few responses where they may occur more than one per year in the study areas. The occurrence of toxic plants in this region become per year might relate to the uni-modal rainy season that boost the growth of these plants only during the rain shower.

The common periods of the year where plant toxicosis is seen in this study: at the beginning of the wet season $(48.6 \%)$, end of rainy season $(32.9 \%)$ and end of the dry season $(12.3 \%)$. This study indicated the existence of high non-infectious health problems such as toxic plants in the area that needs interventions and further toxicology study to reduce livestock exposure and further research to determine the toxicogenic ingredients of the plants.

Shrubs are main source of plant toxicosis(97.3\%) in the study area. It is suggested that, the impact of shrubs as a source of toxicosis compared to trees may be due to the easy availability and access for animals compared to trees, which are not easily accessed. Similarly, a study by Agaie et al. (2007), reported a high proportion of shrubs contribute $(84.2 \%)$ for plant toxicity while only $15.8 \%$ said trees are source of toxicity, although the status of plants was not ascertained here.

For most of the plant toxicosis cases, study participants provide for affected animals the traditional treatments $(63.0 \%)$, than modern veterinary service $(32.2 \%)$. Despite the fact, the proportion of local/traditional treatment is higher; significant number of individuals takes their animals for modern treatment service. Among the top mentioned predisposing factors that expose animals for plant toxicosis in the study area were, food shortage $(43.2 \%)$, accidental ingestion with feed $(40.4 \%)$, nutritional deficiency $(6.8 \%)$, and excess consumption (4.8\%) which is similar with the predisposing factors obtained according to Kebede et al. (2015) on a study conducted in East Wollega Zone of Oromia Regional State, Western Ethiopia. Other reports from other parts of the world indicated feed, nutritional deficiency, water shortages and others factors like sudden graze aggravate the chance of ingesting toxic plants and poisoned water (Seifert, 1969; Radostits et al., 2007; Adediwura and Kola, 2012; Torres et al., 2012; Abera et al., 2014).

In this survey study, 12 common major toxic plants to livestock were identified and documented by their local name. Some of the toxic plants primarily mentioned by the study participants were: Ngiar(32.9\%), Wath(28.1\%), Diir (8.2\%), Magak (5.5\%), Nyuath (4.1\%) and Zom (4.1\%) were the most frequently complained toxic plants in the study areas, which affect cattle, sheep and goats, and cattle $\&$ goats respectively. The toxic plant locally called Ngiar is found widely distributed in range land, farmland, river bank, and backyard areas.

In the present study, the common locations where toxic plants are located in the riverbank (watering point) $(43.8 \%)$, rangeland (23.3\%), backyard (15.8\%), and farmland (14.4\%). On the other hand, Agaie et al. (2007) indicated about 95.4\% study participants replied toxic plants are located around farm/range lands particularly. The other types of toxic plants 
are exclusively found around river banks and water points. Abera et al. (2014) also mentioned most of the toxic plants are located near the farmland together with forage plants.

The most common parts of the plant that causes toxicosis based on the study participants were whole plants and leaves that are similar with Abera et al. (2015), a research conducted in Western Ethiopia. A study in Nigeria stated leaves and barks are highly toxic plant parts among the total body parts (Agaie et al., 2007). Single exposure for toxic plants $(68.5 \%)$ may lead to the abnormal conditions of bloating, circling, death, sudden death; raised hair coats, colic and other signs, despite few may show after second exposure, where Abera et al. (2015) also indicated. This probably indicates the high toxicity capacity of the plants to bring abnormal changes within a single exposure or the dose the animals took during the first ingestion. The impacts vairedfrom simple signs to sudden death.

\section{Conclusions}

The current study showed infectious and non-infectious livestock health problems are among the major constraints for rearing in the areas. Among the non-infectious diseases, plant poisonings are one of the non-infectious livestock health problems in the study areas, that resulting huge loss when animals graze in poisonous plant infested areas of "Lare woreda" and "Itang" special "woredas" of Gambella regional state. This study tried to identify 12 common major toxic plants to livestock were identified and documented by their local name. The common toxic plant groups identified in this study were shrubs followed by tree species. Some of the toxic plants primarily mentioned by the study participants were: Ngiar, Wath (Sorghum arundinaceum), Diir, Magak (Lactuca inermis Forssk), Nyuath and Zom (Ipomoea acquatica Forssk). Other toxic plants identified were Dep gany(Cissus quadrangularis L.), Tach Yaaz (Ipomoae acuatica Forssk) and Hygrophilla schulli (hamilt.) MR. \& S. $M$ Almeida species. The toxic plants were reported in riverbanks (watering point), rangeland, backyard, and farmland areas. Consumption of whole plants and leaves are among the potent toxic parts based on the responses of the findings. Most of the livestock owners tackle plant poisoning through traditional treatment despite there are significant number of owners who are practicing traditional/local treatment for toxic plant affected livestock. Some of the risk factors for plant toxicosis obtained in this study were food shortage, accidental ingestion with feed, nutritional deficiency, and excess consumption.

Based on the present research findings it is recommended to forward the following points

a) There need to be a detailed investigation to know the epidemiology of the poisonings caused by plants

b) Livestock owners should be advised to remove the toxic plants from the watering points, rangeland, backyard and farmland

c) Further toxic plant studies with the analyzing the type of toxin and measuring the toxicity level should be studied.

d) Necessary measures and methods should be taken to tackle the impacts of toxic plants.

e) A systematic integration with appropriate stakeholders should be made to reduce and avoid the impacts of the common toxic plants in the area

f) It is advised to limit or avoid the pre-disposing factor of livestock for plant toxicosis

g) Proper attention towards the toxic plants impacts prevention and control should be given in the areas

\section{References}

[1] Abera D, Jibat T, Sori T, Feyisa A, Beyene T. (2014) Assessment of Plant and Chemical Poisoning In Livestock in Central Ethiopia. J Environ Anal Toxicol 4: 215. doi: 10.4172/2161-0525.1000215.

[2] Abera D., Birhanu T., Abda S. (2015). Survey of Toxic Plants in Livestock at Horro Gudurru Wollega Zone, Western Ethiopia. J BioloAgr and Healthcare. ISSN 2224-3208 (Paper) ISSN 2225-093X (Online). Vol. 5, No. 1.

[3] Abraham Sewonet (2002). "Breaking the Cycle of Conflict in Gambella Region, UN-Emergencies Unit for Ethiopia Assessment Mission: 23-29 December 2002.

[4] Adediwura A., Kola K. (2012). Ethnobotanical survey of toxic plants and plant parts in Ogun State, Nigeria, http://www.greenpharmacy.info/text.asp.2012/6/3/174/10492 6.

[5] Bah, M. S. (2013). The importance of traditional veterinary medicine (TVM) in Animal health programs. In: FAO Corporate Document Repository. FAO.

[6] Clarke, E. C. G., Clarke, M. L.(1977). Veterinary toxicology. Poisonous plants. Cassel and collier, Macmillian publishers. London pp. $268-277$.

[7] CSA.(2007). Central Statistics Authority of Ethiopia. Census 2007 Tables: Gambela Region, Tables 2.1, 2.4, 2.5, 3.1, 3.2 and 3.4.

[8] Deng, Y., Tamir, B., and Asebe, G. (2015). Assessment of Hygienic Milk Production and Prevalence of Mastitis in Dairy Cows in Jikawo Woreda of Nuer Zone, M. Sc Thesis AAU College of Agriculture and Natural Resource, Bishofitu Ethiopia.

[9] Diaz G. J. (2011). Toxic Plants of Veterinary and Agricultural Interest in Colombia, In: Panter EK, and Pfister JA, (Ed.) International Journal of Poisonous Plant Research, A Journal for Research and Investigation of Poisonous Plants

[10] Dixit R (2007). Pharmacokinetics and toxic kinetics: Fundamentals and applications in toxicology. In: Gupta RC (Ed.). Veterinary Toxicology. Basic and Clinical Principles. Academic Press, Waltham West, Erdman and M. W. Emmel (1987). Plants That Poison Farm Animals. Gainesville, FL: University of Florida.

[11] Durairaj P., Kamaraj M., Senthil Kumar S. (2012). Ethno botanical Survey of Folk plants for treatment of snake bite in Tiruchrapalli districts of Tamil Nadu, South India. Int. J. Res. Pharm. Sci. 3(1): 72-78. 
[12] GRS (Gambella Regional State) (2003). Gambella Regional Land-use \& Land Allotment Study. Amended Draft Final Report, Vol. II. Yeshi-Ber Consult (YBC). October 2003, Addis Ababa, Ethiopia.

[13] KebedeA., Zenebe T., Abera D. and Kebede G. (2015). Assessment of Poisonous Plants to Livestock In and Around Nekemte Area, East Wollega Zone of Oromia Regional State, Western Ethiopia. Nat Sci 2015; 13(8): 8-13]. (ISSN: 15450740). http://www.sciencepub.net/nature.

[14] Mugera GM (1970). Phytolaccadodecandral Herit toxicity in livestock in Kenya. Bull Epizoot Dis Afr 18: 41-43.

[15] Ogwang BH (1997). A survey of poisonous plants of livestock in Swaziland. Bull. Anim. Health. Prod. Afr. 45: 99-106.

[16] Puschner B. (2008). Plant Poisonings in Livestock. In: Proceedings, Alfalfa \& Forage Symposium and Western Seed Conference, 2-4 December, 2008, San Diego, CA, UC Cooperative Extension, Agronomy Research and Extension Center, Plant Sciences Department, University of California, Davis 95616.

[17] Puschner B., and Woods L. (2003). Poisonous Plants and Effects on Animals In: Proceedings, 2006 Western Alfalfa and Forage Conference, Sponsored by the Cooperative Extension
Services of AZ, CA, CO, ID, MT, NV, NM, OR, UT, WA, WY. Published by: UC Cooperative Extension, Agronomy Research and Extension Center, Plant Sciences Department, University of California, Davis 95616. (See http://alfalfa.ucdavis.edu for this and other alfalfa proceedings).

[18] Radeleff RD. (1964). Veterinary toxicology. London: Bailliere, Tindall \& Cox, USA

[19] Radostits O. M., Gay C. C., Hinchcliff K. W, Constable P. D. (2007). Veterinary Medicine, A text book of the disease of cattle, horses, sheep, pigs and goats.(10edn), Saunders, Elsevier, London 1851-1895.

[20] Seifert HSH (1969). Tropical Animal Health. Kluwer Academic Publishers, London 470-476.

[21] Tamire H (1997). Desertification in Ethiopian Highlands. RALA Report No. 200. Norwegian Church AID, Addis Ababa, Ethiopia. pp. 162.

[22] Torres P., Diaz J. G., Cárdenas E., Lozano M. C. (2012). Study of ethno botanical Plants Poisonous to Cattle in Eastern Colombia. IJPPR (2): 14-19.

[23] WBISP (Woody Biomass Inventory and Strategic Plan project) (2004). Forest Resources of Ethiopia, Addis Ababa. 